\title{
Conhecimento histórico escolar, tempo presente e o uso de documentos audiovisuais no ensino sobre a ditadura militar na educação básica
}

\author{
Historical school knowledge, present \\ time and the use of audiovisual sources in \\ teaching military dictatorship on basic education
}

Alessandra Carvalho*

Diego Knack ${ }^{* *}$

\section{Resumo}

$\mathrm{O}$ artigo analisa, a partir de experiência realizada em turma de $9^{\circ}$ ano do ensino fundamental de uma escola da rede municipal do Rio de Janeiro, a potencialidade do uso de músicas e da produção de vídeos pelos alunos em torno do tema da ditadura militar. Considerando as contribuições teóricas que sublinham a epistemologia própria do conhecimento histórico escolar em diálogo com as reflexões acerca da presença do tempo presente nas aulas de história, a análise busca examinar as possibilidades do uso de documentos audiovisuais para a aprendizagem histórica.

Palavras-chave: conhecimento histórico escolar; documentos audiovisuais; ditadura militar.

\section{Abstract}

The article analyzes the potentiality of the use of songs and of the production of videos by students about military dictatorship, based on the experience of a $9^{\text {th }}$ grade elementary school class in the city of Rio de Janeiro. Considering theoretical contributions that underline the specific epistemology of historical school knowledge as well as the relevance of present time in history classes today, the analysis examines possibilities of audiovisual sources in learning the historic process.

Keywords: school historical knowledge; audiovisual sources; military dictatorship.

* Doutora em Sociologia pela Universidade Federal do Rio de Janeiro (UFRJ). Professora de História do Colégio de Aplicação (CAp) da UFRJ e professora e coordenadora do Programa de Pós-Graduação em Ensino de História da UFRJ (ProfHistória). Rio de Janeiro, RJ, Brasil. alecarvalho@uol.com.br.

** Mestre em História Social pela Universidade Federal do Rio de Janeiro (PPGHIS/UFRJ). Professor de História da Secretaria Municipal de Educação do Rio de Janeiro (Escola Municipal Anísio Teixeira). Rio de Janeiro, RJ, Brasil. dk.historia@gmail.com 
O conhecimento escolar está longe de dominar o vasto universo de informações e referências disponíveis atualmente aos estudantes por meio de telefones celulares, redes sociais e computadores. Mas, se as evidentes transformações na comunicação refletiram nas maneiras de viver as relações humanas e compreender a realidade, elas não significaram, para a escola, um deslocamento completo de seu papel social. Em outras épocas, igualmente, o processo da educação não foi monopólio da instituição escolar. Segundo conhecida definição do início do século XX, por exemplo, entendia-se a educação como complexa resultante de um "conjunto de ações" - não apenas escolares, portanto - de uma geração sobre outra, que se prepara para o convívio social (Durkheim, 2013, p.53-54). Ainda que se avalie o impacto de novas tecnologias no ensino e se reconheça uma série de variáveis para compreender o fenômeno sociológico da educação, cabe reconhecer que a escola permaneceu como referência principal na formação básica. Nem mesmo o crescimento mais recente de práticas de ensino-aprendizagem que desobrigam a presença integral do aluno, como a educação a distância, prejudicou tal centralidade. Torna-se, então, especialmente relevante discutir o lugar social da escola em nosso tempo e o estatuto epistemológico inerente ao conhecimento construído nela.

No Brasil, transformações políticas e sociais desencadeadas desde os anos 1970 significaram, também, o questionamento dos modelos didáticos vigentes. Nas universidades, que são responsáveis pela formação da maior parte dos professores, houve um progressivo enfrentamento do modelo "instrumental" até então predominante, identificado com as políticas educacionais do período autoritário (Candau, 2012). Segundo esse modelo, a escola básica deveria priorizar a dimensão técnica da aprendizagem no lugar de outras, como a política, social ou humana, para a formação de uma classe trabalhadora eficiente e bem instruída que ocuparia os postos oferecidos no mercado de trabalho. Esse padrão refletiu no privilégio de investimentos para o ensino superior, entendido como ponto de partida do conhecimento científico, em detrimento da formação dos estudantes mais jovens, no "primário" e no "ginásio", enquanto o ensino médio ganhou formato profissionalizante, com o incremento do ensino técnico (Saviani, 2008, p.298). Nessa perspectiva tecnicista e instrumental da didática, o conhecimento escolar é fruto de um conjunto de técnicas e o papel do professor é mais facilmente associado ao da transposição do conhecimento científico para a realidade da educação escolar (Chevallard, 1991). Em 
decorrência disso, o debate sobre a epistemologia própria ao conhecimento escolar restou enfraquecido, pois havia um entendimento predominante de que ele era uma espécie de simplificação do conhecimento acadêmico, sendo a didática, muitas vezes, desprezada ou relacionada somente à busca da melhor técnica para ensinar.

A partir da década de 1980, em contraposição a esse referencial estabelecido, surgiu a proposta de uma didática multidimensional, "fundamental", que valoriza não somente o aspecto técnico, mas também as dimensões humana e político-social do processo ensino-aprendizagem (Candau, 2012, p.14). Nessa leitura, a didática deve ser "situada" no contexto escolar em que se exerce o magistério. A escola é entendida como etapa fundamental do desenvolvimento humano, e o papel do professor é compatível com o de um mediador entre saberes, científicos ou não, a partir dos quais é possível tecer o conhecimento escolar adequado ao contexto em que atua (Lopes, 1999; Maheu, 2001). Disso decorre um conhecimento que tem epistemologia própria, que não é mera simplificação do conhecimento acadêmico, mas resultado de um conjunto de saberes significativos no contexto da formação de jovens adolescentes na escola, o qual depende, para ser mobilizado, da atuação do professor, ainda que evidentemente limitado pelas circunstâncias do contexto em que ele exerce sua prática. Alguns especialistas na área da didática indicam que, embora tenha havido um esvaziamento do modelo instrumental, a noção de uma didática fundamental, marcada pela defesa da existência de distintas dimensões que atuam no processo de ensino-aprendizagem, ainda não teria se consolidado na formação de novos professores (André; Cruz, 2014; Libâneo, 2008). Isso contribui para um quadro de incerteza teórica pedagógica que vem desde a formação dos docentes, pois esses modelos divergem de maneira significativa quanto aos propósitos da escola e ao trabalho do professor.

Em sentido semelhante, na área da História, uma das principais diretrizes com que conta o professor da educação básica para ajudá-lo a pautar o que ensinar, e de que maneira, abre espaço para outras possíveis dúvidas. Trata-se dos Parâmetros Curriculares Nacionais (PCNs), elaborados em 1998, contribuição importante para questionar as abordagens até então estabelecidas, próximas ao modelo "tecnicista", e propor o debate sobre novos caminhos, o que, segundo Carmen Teresa Gabriel, representou algo como o "fim da inocência da historiografia escolar" (Gabriel, 2015, p.43). Mais decisivamente, o 
documento significou uma afirmação das dimensões humana e político-social no ensino e na aprendizagem da disciplina. Os parâmetros indicam, por exemplo, como objetivos gerais do ensino de história na escola "compreender a cidadania como participação política", "adotando atitudes de solidariedade e cooperação diante das injustiças", "posicionar-se de maneira crítica, responsável e construtiva nas diferentes situações sociais", ou ainda "conhecer e valorizar a pluralidade do patrimônio sociocultural brasileiro" (Brasil, 1998). Logo, um grande êxito do texto foi a afirmação de novos caminhos a serem seguidos, embora não tenha alcançado clareza na proposição de um substitutivo teórico eficiente, inaugurando um tempo de tensão entre "o que não mais fazer" e "o que é possível fazer" (Gabriel, 2015, p.53).

Os impasses no estabelecimento de uma orientação teórica para a formação de professores e de parâmetros nacionais para o ensino de história refletem também nas escolas, no conflito entre professores com variados entendimentos sobre suas atuações. Soma-se a isso o caráter não raramente descontínuo de políticas para a educação básica, sendo patente o pagamento de baixos salários aos docentes, a precariedade estrutural de numerosas escolas e, ainda, os problemas em nossas maiores cidades, como a persistência da violência urbana, por exemplo. Disso resulta um cenário que resta, muitas vezes, desestimulante ao professor de jovens e adolescentes. Justamente nesse momento surgem novas tecnologias que, a princípio, parecem rivalizar com a escola no interesse dos alunos e dificultar a já complexa tarefa de ensinar. Não por acaso em vários estados brasileiros foram aprovadas leis que proíbem o uso de celulares em sala de aula, interdição que nem sempre é cumprida e que pode complicar, ainda mais, o debate sobre possíveis aproximações dessas tecnologias de informação ao cotidiano escolar.

Neste trabalho, a discussão se faz sobre possibilidades de emprego de documentos audiovisuais, considerando a utilização das novas tecnologias da informação e comunicação a serviço do que é específico ao conhecimento histórico escolar, adotando a perspectiva de uma didática que se pretende multidimensional, valorizando os aspectos técnico, humano e político-social do processo ensino-aprendizagem. Na primeira seção, tratamos as especificidades do conhecimento histórico escolar e a marca indelével do tempo presente não só na historiografia, mas também nas aulas de história na educação básica. Em seguida, propomos algumas reflexões sobre o ensino da ditadura militar em 
diálogo com as reflexões sobre as singularidades da História do Tempo Presente, para finalizar com a análise de uma experiência desenvolvida com alunos do $9^{\circ}$ ano a partir do uso de músicas e da produção de vídeos.

\section{CONHECIMENTO HISTÓRICO ESCOLAR E O TEMPO PRESENTE}

Preparar uma aula de história para a educação básica envolve buscar o passado e elaborar uma narrativa sobre ele, tal como o ofício de um historiador-pesquisador. Todavia o conhecimento produzido por um historiador-professor envolve procedimentos e finalidades que lhe são característicos, estabelecendo importantes particularidades. Autores como Ana Maria Monteiro, Fernando Penna e Carmen Gabriel têm enfatizado a importância de situar essa elaboração da narrativa em um lugar de fronteira, no qual diferentes saberes oriundos, por exemplo, dos campos da História e da Educação são colocados em diálogo e articulados de maneira particular pelo professor. Dessa forma, diferentes saberes se conjugam no espaço-tempo das aulas de história, o que deriva em um conhecimento escolar específico (Monteiro; Penna, 2011; Gabriel, 2009). A partir de tais abordagens, nas últimas décadas vem se consolidando no Brasil um campo de investigação especificamente voltado para o ensino de história, que pode ser entendido como a

produção dos docentes/agentes culturais em diálogo com seus alunos, em contextos curriculares específicos considerados em seus aspectos contingenciais, nos quais circulam diferentes sentidos e demandas de conhecimento: fluxos oriundos dos conhecimentos científicos que se articulam com referências culturais dos diferentes sujeitos em diálogo e das instituições onde se efetivam as mediações/ produções. (Monteiro, 2015, p.166-167)

Nessa perspectiva, o historiador-professor produz um tipo de conhecimento histórico diferenciado, que não é o mesmo da universidade ou mera simplificação desse - embora com ele deva dialogar. O conhecimento histórico escolar deve ser significativo no contexto em que o professor atua e para os sujeitos com os quais atua, levando em conta, ainda, as demandas de currículo e outras contingências próprias do cotidiano da escola. Na radicalidade dessa concepção, é possível afirmar que as aulas de história adquirem caráter 
duplamente autoral na medida em que, por um lado, traduzem as seleções de historiografia e de práticas didáticas e curriculares feitas pelos professores em contextos culturais e escolares dados, mas que, por outro lado, só se realizam em diálogo com os seus alunos, os quais também criam a aula com suas escolhas, demandas e interpretações. Por isso, Ilmar de Mattos sublinha que a aula de história “é criação individual e coletiva a um só tempo" (Mattos, 2006, p.14).

Por sua relação intrínseca com o presente em que o historiador-professor atua é que a tarefa de elaborar aulas de história na educação básica está inextrincavelmente ligada à História do Tempo Presente, independentemente do tema em questão (Monteiro, 2015, p.168), pelo fato de o professor tornar, em suas narrativas de sala de aula, "contemporâneo, o não contemporâneo" (Dosse, 2012) e atual o passado, em "permanente processo de atualização" (Delgado; Ferreira, 2013, p.25). E o professor pode transitar, com talvez mais liberdade que o historiador-pesquisador, entre diversos contextos culturais e temporais para confecção de suas narrativas, utilizando, para isso, variadas estratégias para sua mediação didática, sem que isso prejudique suas finalidades na construção do conhecimento.

Todavia, é importante sublinhar que não só o professor, na produção de sua narrativa didática sobre o passado, "traz consigo as marcas de sua época ... [fazendo do] tempo presente ... uma contínua presença e uma necessidade do discurso historiográfico" (Silva, 2017, p.101). Se, retomando as ideias de Mattos, consideramos a aula de história como uma criação coletiva da qual participam professores e alunos, estes também impõem o tempo presente com suas experiências, anseios, linguagens, culturas; com o vídeo assistido no YouTube ou recebido pelo WhatsApp, com a série que viram em algum canal de TV, ou algo que leram no jornal, o acontecimento que movimentou seu bairro, a música que escutaram no Spotify etc. Nesse âmbito, uma das preocupações centrais do historiador-professor deve ser a de estabelecer pontes entre seu universo simbólico, o conhecimento histórico que pretende apresentar e os contextos nos quais o estudante está inserido, em seus saberes, interesses e valores.

São pontes que caminham em duas direções. Na primeira delas, é importante considerar os distintos usos do passado que emergem dos contextos e saberes dos alunos, oriundos de procedimentos diversos e, alguns deles, estranhos ao métier do historiador-professor. Nessas situações, intensifica-se a importância e a responsabilidade do professor na tarefa de estabelecer um 
espaço próprio da história escolar, capaz de ajudar o aluno a se apropriar criticamente daquilo que lê, vê e escuta nas diferentes mídias. Para isso, é crucial que as distintas narrativas sobre o passado sejam trabalhadas pelos professores como documentos históricos, que precisam ser contextualizados e cujo processo de produção deve ser analisado. A ponte aqui se faz no diálogo e na distinção entre os diferentes usos do passado presentes na sociedade, demarcando o que é próprio da história escolar e pode aprofundar a capacidade dos alunos de compreender o mundo em que vivem. Na segunda direção, a ponte se constrói na possibilidade de apropriação, pelo professor, das linguagens que fazem parte do cotidiano do aluno, considerando não só o seu uso em atividades didáticas, mas também a sua produção em sala de aula como forma de aprendizagem da história.

É nesse sentido que o recurso aos documentos e às linguagens audiovisuais pode representar um potencial caminho de êxito para alcançar objetivos pedagógicos no ensino de história na educação básica. Não como um fim em si mesmo, que figure como espécie de elogio da primazia do tecnológico, mas antes como meio para despertar o interesse dos estudantes, familiarizados com recursos como músicas, imagens e vídeos, tão comuns em nosso tempo, para questões próprias do conhecimento histórico. E também como forma de produzir estranhamento diante desse tipo de linguagem que, de tão comum, muitas vezes é naturalizada (Sarlo, 2013, p.71), transformando-a em uma produção social a ser debatida.

Quando o tema é ditadura militar brasileira, a aproximação pode se revelar ainda mais oportuna. Novelas, séries, documentários, videoaulas, canais do YouTube e imagens compartilhadas em redes sociais, além das memórias de familiares que viveram aquela época, são referências frequentes entre os conhecimentos prévios dos estudantes nas aulas de história. Convidá-los à crítica e à reflexão, ainda que inicial, sobre esses diversos saberes, é importante ponto de partida para o conhecimento histórico especificamente escolar.

\section{A Ditadura Militar EM SAla DE AUla: \\ UMA HISTÓRIA SEMPRE PRESENTE}

Até aqui, o tempo presente tem sido tratado como elemento constitutivo do contexto de produção de narrativas sobre o passado, seja em sua forma 
acadêmica ou escolar. Outro registro, entretanto, se estabelece quando direcionamos a atenção para o ensino dos processos históricos que fazem parte da História do Tempo Presente, relacionados ao século XX e, sobretudo, aos chamados "temas sensíveis" - tais como as duas guerras mundiais, o Holocausto, o Apartheid e os regimes ditatoriais na América Latina. De imediato, um aspecto a destacar é a profusão de narrativas sobre esses processos produzidas por diferentes profissionais: jornalistas, escritores de ficção e diretores de cinema, entre outros. Um breve levantamento das distintas produções acerca da ditadura militar do Brasil nos últimos anos demonstra como o tema é constantemente tratado na televisão e na literatura, em obras de ficção e jornalísticas; no cinema, encontra-se uma dinâmica semelhante, com o lançamento de filmes de ficção e documentários de enfoque bastante diversificado, sem contar a enorme produção audiovisual destinada à veiculação na internet. Em outra dimensão da vida social, as narrativas sobre o período ditatorial estão presentes nas intensas disputas políticas que tomaram conta do país desde o ano de 2013, ora como parâmetro do que deve ser evitado nos conflitos políticos, ora, infelizmente, como paradigma de uma "ordem social estável”.

Os usos do passado ditatorial se multiplicam e chegam aos alunos e às salas de aula por variados caminhos, gerando dúvidas e questionamentos entre os estudantes e a pressão por um posicionamento do professor (Rocha, 2009, p.23). Pressão essa que conjuga elementos de caráter ético-político, na medida em que estão em cena memórias e demandas de grupos e indivíduos que foram submetidos a violências e sofrimentos pelo governo ditatorial, e do conhecimento acadêmico, que analisa de maneira crítica a própria emergência e conformação dessas memórias. Nessa fronteira sensível entre o ético, o político e o acadêmico, na qual o professor atua, antes que encontrar uma equação definitiva, um caminho de atuação possível é pensar em como construir didaticamente essa imbricação entre história e memória que caracteriza a história do tempo presente e da ditadura militar (Fico, 2012, p.48). Em outras palavras, como elaborar situações didático-pedagógicas nas quais seja possível destacar e fazer dialogar os distintos usos do passado ditatorial, preservando a finalidade precípua da história escolar de desnaturalizar as produções sociais e fortalecer a capacidade crítica dos alunos diante da miríade de narrativas e informações sobre esse período. 
Nessa perspectiva, o uso de documentos históricos é importante recurso para trabalhar essa história tão presente e tão disputada nos dias atuais. Documentos tais como filmes, canções, livros de ficção e relatos orais são fundamentais para que se possam compreender e analisar as diferentes memórias e narrativas elaboradas sobre o período ditatorial. Essa proposta nos remete a um segundo aspecto distintivo da História do Tempo Presente, que se refere à centralidade ocupada pelos testemunhos, considerando também aquele do historiador-professor que compartilha a experiência do tempo com seu objeto. É comum que os professores, discutindo questões relacionadas à ditadura militar, coloquem-se, eles mesmos, como testemunhos desse tempo expressando suas próprias memórias - até como recurso argumentativo do conhecimento que pretendem construir. A utilização de testemunhos em sala de aula - em vídeos, com a presença de pessoas com trajetórias particulares na escola ou mediante entrevistas realizadas pelos alunos - oferece uma possibilidade de construção específica do conhecimento histórico, marcada pela perspectiva individual e pelas cores dos sentimentos, às vezes tão distantes das narrativas da história na educação básica, as quais enfocam categorias coletivas e abordagens mais gerais.

A riqueza do uso de testemunhos em sala de aula se realiza, também, em outra dimensão. Se, como já pontuado, história e memória estão imbricadas na história no tempo presente, é possível elaborar atividades em que os alunos, tais como os historiadores, busquem refletir sobre o que é particular a cada uma e como elas se relacionam. Dialogando com as afirmações de Caimi,

o ensino de história deve ter como parte de suas preocupações a administração das recordações, relatos e transmissões do passado, auxiliando os alunos a desenvolverem habilidades de pensamento e instrumentos para evitar as naturalizações do passado e a mera recepção das tradições herdadas. (Caimi, 2009, p.73)

A análise crítica dos testemunhos e das memórias que eles expressam sobre a ditadura militar permite ao professor construir com os alunos atividades relacionadas às maneiras de a história trabalhá-los como um documento, uma produção humana no tempo, abrindo espaço para o estranhamento necessário à desnaturalização do que se vê e ouve. Nesse sentido, tem-se a oportunidade de colocar em marcha um movimento de diferenciação entre aquilo que é narrado pelos testemunhos e a maneira como se produz o conhecimento histórico. Essa 
operação é fundamental, sobretudo, quando se registra atualmente uma intensa produção acerca do passado histórico por outros profissionais. Possibilitar que os alunos experimentem procedimentos do historiador é, portanto, apostar no desenvolvimento da capacidade de se apropriar das narrativas veiculadas na sociedade de maneira mais qualificada e autônoma. No caso da ditadura militar, é também uma maneira de contextualizar e "organizar" a polifonia de usos desse passado verificada atualmente.

\section{ANALISANDO DOCUMENTOS HISTÓRICOS E PRODUZINDO} CONHECIMENTOS: VÍDEOS INTERPRETATIVOS BASEADOS EM MÚSICAS DO PERÍODO Ditatorial - O "Festival da CANÇão"

"Professor, posso estudar pelo YouTube?" "Professor, por que não fazemos um vídeo sobre ditadura?”, "Ou uma paródia daquela música?” "Viu aquela série de História que passou na TV?” Estas são perguntas que não devem soar estranhas a professores de história na educação básica. Partindo delas e dos interesses que elas revelavam, surgiu a proposta de realizar um trabalho escolar que contemplasse: (1) uma atividade de pesquisa com músicas que tiveram seu lançamento no período da ditadura militar brasileira; e (2) a produção de um vídeo interpretativo com base no conhecimento adquirido.

Antes de considerar de forma mais aproximada essa atividade, cabe indicar algumas referências pertinentes ao tratamento teórico-metodológico de documentos audiovisuais, especialmente no caso da música. Segundo Mariana Villaça, a canção é um

complexo conjunto composto pelos elementos musicais por excelência: harmonia, ritmo, melodia, arranjo, instrumentação - e por uma série de outros elementos que compõem sua forma: a interpretação e os signos visuais que formam a imagem do intérprete, a performance envolvida, os efeitos timbrísticos e os recursos sonoros utilizados na gravação ... a estes elementos acrescenta-se a letra da canção e toda a sua complexidade estrutural, na medida em que qualquer signo linguístico, associado a um determinado signo musical, ganha outra conotação semântica, que extrapola o universo da compreensão da linguagem literária. (Villaça,1999, p.330) 
Nesse sentido, Marcos Napolitano alerta para o perigo da redução da música à sua letra, atribuindo-se menor importância à proposta estética, ao ritmo e outros componentes da linguagem musical. Interpretar uma canção envolve, além disso, "uma tensão entre subjetividade e objetividade, impressão e testemunho, intervenção estética e registro documental" (Napolitano, 2005, p.236). Diante disso, o autor avalia os cuidados específicos na utilização de canções como documentos históricos. Para ele, esses vários significados das músicas, esse caráter polissêmico "não é um obstáculo intransponível, e as possibilidades de trabalho do historiador ancoram-se no mapeamento das 'escutas históricas' (crítica, público e os próprios artistas, que são também ouvintes) que dão sentido histórico às obras musicais" (Napolitano, 2005, p.258).

Ou seja, não basta o procedimento heurístico da crítica interna - a análise de letra, melodia, composição musical, fonogramas etc. - para a satisfatória interpretação histórica das canções. Faz-se igualmente necessário perceber leituras externas às obras, como condições de produção, referenciais estéticos e de mercado, bem como memórias, individuais e coletivas, consagradas em "escutas" do material produzido. Somente dessa maneira, com a busca desse caráter multifacetado do documento musical, é possível apreender os vários significados históricos possíveis, ao menos os mais recorrentes e, a partir desses, construir narrativas consistentes sobre o passado que se quer analisar com base na canção.

Em direção semelhante, Soares afirma a potencialidade do uso de músicas nas aulas de história, relacionando-a ao próprio espaço que a música ocupa na vida dos alunos, mas sublinha que o professor deve definir com muita acuidade seus objetivos no manejo desses documentos multifacetados. Assim, pontua a importância de distinguir e definir didaticamente ações voltadas não só para a discussão da letra das canções e de seus aspectos rítmicos e estéticos, como também para a maneira "como os alunos interagem com as músicas e os gêneros musicais” (Soares, 2017, p.83). Nessa concepção, abrir espaço para a expressão da experiência e das culturas musicais dos estudantes é um passo fundamental para desenvolver atividades com músicas em sala de aula, inserindo um componente afetivo e subjetivo para pensar a utilização desses documentos.

Em princípio, a admissão desses procedimentos sugere a alta complexidade desse tipo de crítica documental. Considerado o contexto escolar, poderia 
parecer uma tarefa quase impossível, especialmente se realizada por jovens e adolescentes sem nenhuma formação aprofundada nesse tipo de investigação. Todavia, devemos assumir a viabilidade de tratar essas questões em sala, ainda que movimentos de interpretação histórica internos e externos ao documento se apresentem ao aluno de forma imbricada. Isto é, admitir a possibilidade do recurso a esse tipo de documentação, mesmo que o historiador-professor, em conjunto com seus estudantes na sala de aula da educação básica, não consiga abarcar toda a complexidade que fontes dessa natureza sugerem ao historiador-pesquisador. Isso porque, como já se afirmou, o conhecimento histórico escolar tem epistemologia própria, forjada no contexto do magistério de um historiador-professor com seus alunos. Desse modo, se a utilização de músicas como documentos históricos servir ao alcance dos objetivos pedagógicos do docente, seu emprego é válido. $O$ recurso às canções pode servir, por exemplo, à formulação de questões a serem debatidas coletivamente, à complexificação das narrativas históricas construídas sobre determinado passado, à proposição de aulas diferenciadas, além de várias outras finalidades específicas possíveis que levem a oportunizar a construção de elos simbólicos entre o estudante e os conhecimentos pretendidos.

\section{a) Planejamento - Definindo tempos de aprendizagem e estratégias}

Com base nesses entendimentos preliminares, realizou-se uma atividade denominada "Festival da Canção" envolvendo três turmas do $9^{\circ}$ ano do ensino fundamental de uma escola da rede municipal do Rio de Janeiro. O nome escolhido foi uma forma de se referir aos festivais da canção, bastante populares no Brasil durante a década de 1960, e, ao mesmo tempo, diferenciar, desde o início, essa proposta das demais ações do cotidiano escolar estabelecido.

A escola se estrutura em um turno único: os estudantes ingressam às $7 \mathrm{~h} 30$ e saem às $14 \mathrm{~h} 30$, tendo momentos de socialização, como o recreio e o almoço, realizando refeições no local. Após as $14 \mathrm{~h} 30$, têm a opção de ficar mais duas horas para realizarem tarefas ou se engajarem em alguma das oficinas temáticas oferecidas, voltadas ao esporte, como futebol e tênis de mesa, e à música, em uma banda e uma orquestra de câmara. Em geral, muitos dos alunos que frequentam essa escola habitam próximos uns aos outros, em comunidades da Zona Norte da cidade, e convivem, também, fora da escola. Apresentam, ainda, interesse em videogames, celulares, vídeos, filmes e tecnologia. Não por acaso, 
ali há professores que empregam de forma recorrente a linguagem audiovisual em suas estratégias de docência e que contam com o respaldo e apoio da equipe de direção, além da estrutura básica para tal, como caixa de som e projetor em cada sala, embora a disponibilidade de internet seja intermitente. A escola conta, ainda, com um cineclube e uma sala de jogos. Outro elemento de interesse para o planejamento da atividade proposta - e que se deve, por isso, destacar - é a presença comum dos fones de ouvido pessoais juntos ao uniforme, o que indica uma vivência atrelada às várias canções, seja em gênero de funk, rap, pagode, samba ou músicas de cunho religioso.

Esses dados específicos do contexto escolar são de grande relevância para a realização bem-sucedida da atividade, devendo, pois, ser considerados no momento do planejamento. Como já destacado neste texto, a estratégia didática do docente deve ser adequada às possibilidades de atuação apresentadas. Em realidades diferentes, é possível que outros procedimentos tenham de ser considerados para o alcance dos objetivos propostos. Em termos de planejamento didático específico ao conhecimento histórico escolar mobilizado, os objetivos dessa atividade foram:

1) Caracterizar o período da ditadura militar pela prática de censura, espionagem e repressão política pelo Estado brasileiro;

2) Diferenciar regimes políticos ditatoriais de democracias;

3) Identificar grupos sociais que foram alvo de investidas autoritárias durante as décadas de 1960 e 1970;

4) Caracterizar o engajamento político de parte, não da totalidade, da produção musical da ditadura;

5) Delimitar conjunturas políticas específicas da ditadura brasileira, como o golpe, os chamados "anos de chumbo" e a "abertura política".

A atividade foi realizada em turmas com cerca de 35 alunos cada. Em cada uma, foram designados três grupos grandes, cada um responsável pelo estudo e produção de vídeo interpretativo de uma música. Inicialmente, foram escolhidas nove canções para a realização do "Festival da Canção", divididas em temas pretendidos. 
Quadro 1 - Lista das músicas escolhidas

para a atividade "Festival da Canção":

\section{Tema 1: Repressão}

a) Opinião - Zé Keti (1964)

b) Pra não dizer que não falei das flores - Geraldo Vandré (1968)

c) Cálice - Chico Buarque e Gilberto Gil (1978)

Tema 2: Anos 60/70

a) Quero que vá tudo pro inferno - Roberto Carlos (1965)

b) Top Top - Mutantes e Arnolpho Lima Filho (1971)

c) Mosca na Sopa - Raul Seixas (1973)

Tema 3: Abertura Política

a) O bêbado e a equilibrista - João Bosco e Aldir Blanc (1979)

b) Tô voltando - Maurício Tapajós e Paulo César Pinheiro (1979)

c) Inútil - Roger Moreira (1985)

O critério da escolha das músicas foi, basicamente, temático. Algumas porque, segundo as leituras mais correntes sobre a letra, melodia e suas condições de produção, enfatizavam, especialmente, a questão da repressão. Outras foram escolhidas por tratarem diferentes perspectivas musicais e estéticas do período, que não estivessem, necessariamente, conectadas à temática do engajamento político. E, ainda, as últimas eram voltadas especificamente para o processo de abertura política. Buscou-se atingir diferentes perspectivas musicais e temporais como forma de trabalhar a noção de que são várias as possibilidades de conhecimento histórico sobre o período, objetivando-se fugir às leituras maniqueístas, comuns às memórias, e que é tarefa do conhecimento histórico escolar superá-las enquanto únicas vias de representação do passado (Delgado; Ferreira, 2013, p.31). Designou-se pelo menos uma música de cada tema para cada turma, a fim de preservar a variedade temática. Em seguida, definiu-se o tempo necessário para execução e as estratégias adotadas. Ao final, foram utilizados 14 tempos de aulas, com 50 minutos cada, para realização das atividades, divididas desta forma: 
Quadro 2 - Atividades programadas do "Festival da Canção"

Procedimentos

- 2 tempos - Introdução da proposta, divisão dos grupos, sorteio das músicas

Exibição de pequeno vídeo da apresentação de Roda Viva no Festival da Canção de 1967, para explicar a referência no título da atividade, elucidação da proposta e dos critérios de avaliação, divisão dos grupos de trabalho e sorteio das músicas.

- 4 tempos - Pesquisa histórica orientada

Em sala, conforme combinado previamente, alunos pesquisam sobre o contexto de composição da música, as trajetórias de seus autores e preenchem a ficha de pesquisa.

- 2 tempos - Apresentações preliminares das músicas/ pesquisas

Cada grupo apresenta os resultados sobre a pesquisa histórica referente à sua música e a turma ouve as músicas.

- 4 tempos - Produção dos roteiros e dos vídeos

Noções de roteiro, produção e edição para dar suporte aos alunos na produção do vídeo interpretativo. Alunos produzem roteiro em sala sob orientação do professor. A gravação ficou sob responsabilidade de cada grupo.

- 2 tempos - Apresentações finais

Apresentação dos vídeos produzidos e avaliação geral da atividade.

\section{b) Execução - Alunos pesquisam, planejam vídeo e gravam}

No momento da apresentação do vídeo de Roda Viva no festival de 1967, houve um estranhamento imediato. A imagem em preto e branco, a figura de jovens em terno e gravata em volta de uma plateia bastante agitada e que canta uma canção que soa exótica aos alunos ouvintes gerou, nas três turmas, uma primeira tensão, espécie de desconfiança. Se afirmamos a necessidade de trânsito entre os interesses dos alunos e a afetividade estabelecida com as músicas 
de que gostam, devemos considerar que esse impasse inicial poderia levar os estudantes a uma espécie de bloqueio e desinteresse, o que colocaria em risco tudo o que foi proposto.

No entanto, se por um lado as músicas de um passado tão distante puderam soar como "velhas", por outro, a possibilidade da criação de um vídeo em que iriam atuar e estariam livres para interpretar aquele documento musical - apropriando-se, pois, de parte de seus significados - despertou o interesse de muitos. Desse modo, ao mesmo tempo que se manifestou a alteridade no estranhamento do som, do ritmo, da letra e da proposta estética de outros tempos, houve identidade, aproximação, diante da linguagem audiovisual, contemplada pela proposição do vídeo interpretativo. Alguns alunos quiseram logo "aparecer" no clipe que seria produzido, enquanto outros já mostraram a preferência pela pesquisa, para não atuarem na gravação. De todo modo, quando apresentada a proposta completa, pareceram envolvidos na ideia de produzir, eles mesmos, uma nova leitura sobre o que estava sendo apresentado. Dito de outra forma: poderiam protagonizar interpretações sobre o passado e estariam diante da oportunidade de aprender história de um jeito diferente daquele ao qual estavam mais acostumados.

Em seguida, foram designadas aos estudantes três tarefas: o preenchimento de uma ficha de pesquisa sobre a música, a produção de um roteiro escrito e de um vídeo interpretativo da canção selecionada para o grupo.

Quadro 3 - Festival da Canção: Ficha de pesquisa histórica

\begin{tabular}{|l|l|}
\hline Nome da canção & \\
\hline Autores & \\
\hline Intérprete & \\
\hline Ano de lançamento & \\
\hline Sofreu censura? Por quê? & \\
\hline Sobre o contexto histórico do ano do lançamento & \\
\hline Relação entre a canção (letra/melodia) e o contexto histórico & \\
\hline Fontes consultadas na pesquisa & \\
\hline Alunos responsáveis pela pesquisa / Turma & \\
\hline
\end{tabular}


O preenchimento da ficha de pesquisa requer a mobilização dos conhecimentos históricos trabalhados em aulas anteriores sobre a ditadura militar. De modo semelhante, implica a percepção da música como documento histórico cuja interpretação servirá tanto ao alcance dos objetivos pedagógicos propostos para a atividade quanto à caracterização da história como investigação sobre o passado. Nesse estágio, é de fundamental importância a orientação contínua do professor diante da precisão das informações apuradas pelos grupos, bem como das fontes utilizadas na pesquisa. Após o preenchimento dessa ficha de pesquisa, é importante que os estudantes apresentem os resultados obtidos, como forma de consolidar o conhecimento alcançado.

$\mathrm{Na}$ atividade de pesquisa orientada e na apresentação preliminar da canção, as maiores dificuldades surgiram na interpretação de figuras de linguagem complexas que algumas das canções selecionadas utilizam, assim como no estabelecimento da relação com o contexto histórico da ditadura. Pra não dizer que não falei das flores menciona soldados "armados, amados, ou não", enquanto Cálice trata de "beber bebida amarga" ou "danar-se na calada da noite", e O bêbado e a equilibrista de uma tarde que cai "feito viaduto", por exemplo. Em casos como esses, foi necessário ajudá-los a contextualizar algumas informações e orientá-los na inferência sobre os possíveis significados de algumas metáforas e metonímias, tomando sempre o cuidado de não estabelecer leituras únicas e de estimular o aluno à interpretação nas múltiplas dimensões do documento musical. Em outros casos, como em Top Top, Quero que vá tudo pro inferno e Mosca na Sopa, especialmente, foi preciso orientar sobre a relação dos documentos com outras músicas do período, identificando diversas orientações estéticas com as quais havia evidente diálogo, como a Jovem Guarda, a Tropicália ou o rock n'roll. A identificação da pluralidade de expressões musicais e experiências históricas, assim como a ampliação da pesquisa histórica, contribuíram para a percepção de um cenário mais complexo do que talvez parecera ao primeiro olhar das aulas de história anteriores.

\section{Produção de roteiro}

A produção de um novo tipo de narrativa e de documento, agora audiovisual - não mais o registro musical de origem ou narrativas e memórias sobre o passado em estudo -, gera um tipo de uso do passado bastante fértil, agora em prol do desenvolvimento do senso crítico dos estudantes da educação 
básica diante de linguagens dessa natureza e do estabelecimento de algumas interpretações possíveis sobre o passado da ditadura militar, com base na investigação de vários tipos de fontes.

O próprio ato de planejar a produção audiovisual - de verso em verso, de alguns compassos musicais a outros e, no vídeo, de cena em cena - contribui para a discussão do material entre os alunos em grupo e o aprofundamento do movimento interpretativo. Novamente, a mediação docente mostra-se essencial para alertar os estudantes sobre a organização, a viabilidade e a pertinência das soluções visuais propostas. No planejamento do vídeo de Opinião, um dos alunos mais ativos de um dos grupos deu a ideia de encenar a prisão e tortura de um oponente da ditadura. A dificuldade que se apresentou foi, portanto, de como representar esse dado tão delicado daquele passado, a experiência da tortura. A solução encontrada, depois de muito debate, foi a de encenar uma passeata em que um grupo de estudantes seria preso e, na cena seguinte, seria mostrado ao espectador um militar com uniforme manchado de tinta vermelha, em alusão ao sangue, resultado de violência. Nessa etapa, outro integrante do grupo sugeriu que, para essa cena, a câmera fosse posicionada no chão, próxima ao coturno, enquanto a tinta apareceria no chão sendo, logo em seguida, apagada. O acordo sobre essa solução visual específica permitiu ao vídeo daquele grupo uma menção cuidadosa ao grave problema da tortura, ao mesmo tempo que realizaram uma denúncia da ocultação dessa terrível prática por agentes das Forças Armadas durante a ditadura.

Outro grupo, responsável pelo vídeo sobre a canção Inútil, decidiu empregar imagens comumente replicadas na internet com finalidade humorística, os chamados memes, para reforçar uma leitura possível sobre o documento, o de que tal música era uma crítica ácida ao fato de que os jovens brasileiros do início dos anos 1980 não podiam escolher o presidente do país, sendo pois "inúteis", como sugerem, igualmente, os provocados erros de concordância verbal e nominal no verso do refrão “A gente somos inútil”. Muitos outros exemplos semelhantes seriam possíveis, porque o debate em torno do roteiro contribuiu para consolidar não só alguns saberes específicos ao audiovisual, como posicionamento da câmera, edição, storytelling - ainda que não necessariamente enunciados desse modo -, mas também o conhecimento histórico escolar sobre o tempo da ditadura. 


\section{Produção e edição do vídeo}

A tarefa de produção e edição dos vídeos ficou designada como extraclasse. No contexto escolar em que foi proposta, isso era possível uma vez que um grande número de estudantes possuía celulares e conhecimentos prévios sobre o assunto. Como já mencionado, eles podiam ficar além do horário das aulas regulares, para realização das gravações. A maioria dos alunos escolheu gravar depois do horário na própria escola, como forma de aproveitar o espaço e a estrutura. Utilizaram tanto o espaço externo da escola, uma quadra, como os internos - escadas, corredores e salas. Em um dos vídeos, a grade que tranca a quadra da escola serviu para simulação de uma cadeia. Em outro, o pátio exterior serviu de cenário para uma suposta manifestação. Ainda, a sala de leitura serviu para a encenação de um interrogatório, em Cálice. Todas essas foram escolhas dos estudantes na produção do vídeo, soluções estéticas para cumprirem a proposta do trabalho. Os alunos escolheram, ainda, roupas e elementos disponíveis no acervo do camarim das aulas de teatro para compor o cenário do vídeo, como coturnos, uniformes militares, ternos, gravatas, chapéus etc. Muitos dos grupos, sob orientação do professor, escolheram um aluno para ser o diretor da produção, responsável por manter acessível o roteiro e orientar a gravação das cenas e os movimentos previstos.

A captação das imagens foi realizada com os celulares pessoais dos estudantes. Entre eles, mesmo os aparelhos mais simples se mostraram eficazes para realizar o trabalho. A qualidade do áudio - que normalmente preocupa nesse tipo de vídeo, pois exigiria equipamentos mais específicos, como um microfone direcional ou boom -, também não trouxe problemas, pois os áudios que serviram de base para o material produzido foram as canções em suas interpretações originais.

Três grupos, responsáveis por Top Top, Mosca na sopa e Tô voltando, decidiram gravar fora da escola, tendo enfrentado, talvez por isso, maior dificuldade em completar a tarefa no prazo estipulado. Do mesmo modo, coube ao professor sugerir em alguns trabalhos diferentes formas de captação de imagem ou edição. Em Top Top, por exemplo, sugeriu-se a sincronia dos movimentos propostos pelos alunos às batidas rítmicas da música, ocasionando outro impacto a quem assistiu. Em Mosca na Sopa, o grupo teve a ideia de encenar uma pessoa caminhando no meio da rua e sendo, então, perturbada 
pelo zumbido do inseto, que parecia sugerir ao transeunte que caminhasse à esquerda, o que era, segundo o grupo, uma alusão ao posicionamento político de oposição à ditadura. Para melhor atendimento dessa intenção, sugeriu-se um enquadramento mais amplo - um plano geral, no jargão técnico - o que possibilitou uma visão mais geral da proposta no início do vídeo, depois sendo alternado com imagens mais próximas dos atores - em plano detalhe.

É interessante notar que os alunos com mais facilidade no manejo das ferramentas de captação e edição de vídeos se disponibilizaram a ajudar os demais grupos, de modo que não foi necessária muita intervenção do docente nesse sentido. Apenas em uma das turmas se fez necessária, no entanto, intervenção para indicar os usos básicos de ferramentas e aplicativos de edição de vídeo, facilmente dispostas na internet.

\section{c) Avaliação - Verificação dos conteúdos e produto final}

$\mathrm{Na}$ ocasião marcada para a exibição dos vídeos em cada turma, foi evidente a empolgação de muitos estudantes pelo fato de serem vistos na tela grande de exibição dos trabalhos finais diante de seus colegas de classe. Foi uma experiência diferente. Tais particularidades das adolescências na escola, como a preocupação com a aparência, a autoestima diante do corpo em transformação ou a convivência com os colegas no grupo da turma, não deve ser deslocada do processo de construção do conhecimento escolar. Durante a exibição, os alunos aplaudiram em diversos momentos, riram de erros de gravação, silenciaram em momentos mais tensos, em reações que denotaram envolvimento com a atividade proposta.

Durante todo o processo, foi possível avaliar o alcance dos objetivos iniciais. A entrega do vídeo foi, entretanto, um momento privilegiado de avaliação, a partir do qual foi possível finalizar a atribuição das médias (notas) dos alunos naquele bimestre. Quando foram convidados a falar sobre a experiência da gravação, relataram tanto as dificuldades destacadas neste texto como a satisfação na vivência com os colegas durante o processo de produção do vídeo. Essa foi, também, outra oportunidade para avaliar o alcance dos objetivos específicos ao conhecimento histórico, isto é, se sabiam caracterizar regimes autoritários em comparação com as democracias, notar diferentes experiências sociais, políticas e culturais na ditadura brasileira - logo, também estéticas - e de movimentos culturais dos anos 1960 e 1970, assim como diferenciar 
conjunturas históricas específicas, do golpe, do arrefecimento das práticas repressivas e do processo de abertura política.

\section{CONSIDERAÇÕES FINAIS: SOBRE \\ HISTORIADORES-PROFESSORES EM SEU TEMPO}

Após as considerações apresentadas, parecerá evidente que ensinar sobre ditadura militar na educação básica permanece um grande desafio. Em especial diante da imensa diversidade de produtos audiovisuais que evocam tal passado, verdadeira "avalanche de informações e formas contemporâneas de comunicação social (Rocha, 2009, p.33), ou das tantas dificuldades que permeiam a realidade das escolas brasileiras. $\mathrm{Ou}$, ainda, diante das especificidades impostas pela escrita da história de um tempo que ainda não acabou, uma História do Tempo Presente, que, em sua prática escolar, reitera enfaticamente nos docentes a necessidade constante de se posicionarem ética e politicamente, o que já é inerente ao ofício de ensinar.

Todavia, a identificação desses desafios não deve inibir o enfrentamento de tais questões. Historiadores entre jovens e adolescentes, historiadores-professores, não devem se furtar aos grandes temas de seu tempo na produção do conhecimento histórico escolar, lançando mão, se necessário, das linguagens audiovisuais disponíveis, nos termos estabelecidos em seu contexto escolar de atuação, para obterem maior êxito nos processos de ensino-aprendizagem que conduzem. A familiaridade simbólica ao audiovisual, se associada à tarefa de crítica documental e pesquisa histórica, pode, desse modo, oportunizar a construção de um conhecimento histórico escolar mais consistente, ao mesmo tempo que desperta, ou reforça, o interesse de estudantes pelo passado.

Nesta proposta, o uso de documentos históricos é central na tarefa de construir um ensino de história no qual os alunos possam atuar de maneira criativa e científica, experimentando, mediados pelo professor, o método do historiador no que se refere à compreensão do que é um documento, de sua complexidade, das possibilidades de sua interpretação. Por fim, tornando-se, também, produtores de conhecimento e autores da história que aprendem. 


\section{REFERÊNCIAS}

ALEXANDRE, Ricardo. Dias de luta: o Rock e o Brasil dos anos 80. Porto Alegre: Arquipélago, 2013.

ANDRÉ, Marli Eliza D. A. de; CRUZ, Giseli Barreto da. Ensino de didática: um estudo sobre concepções e práticas de professores formadores. Educação em revista, Belo Horizonte, v.30, n.4, p.181-203, out./dez. 2014. Disponível em: http://www.scielo. br/scielo.php?pid=S010246982014000400009\&script=sci_abstract\&tlng=pt; Acesso em: 2 jul. 2017.

BRASIL. Ministério da Educação. Secretaria de Educação Fundamental (SEF). Parâmetros curriculares nacionais: história. Brasília, 1998.

CAIMI, Flávia Eloisa. História escolar e memória coletiva: como se ensina? Como se aprende? In: ROCHA, Helenice et al. A escrita da história escolar: memória e historiografia. Rio de Janeiro: Ed. FGV, 2009. p.65-79.

CANDAU, Vera (Org.) A didática em questão. Petrópolis: Vozes, 2012.

CHEVAllaRD, Yves. La Transposition Didactique. Grenoble: La Penseé Sauvage, 1991.

DELGADO, Lucília de A. N.; FERREIRA, Marieta de M. História do Tempo Presente e ensino de história. Revista História Hoje, v.2, n.4, p.19-34, 2013. Disponível em: https://rhhj.anpuh.org/RHHJ/article/viewFile/90/70; Acesso em: 2 jul. 2017.

DOSSE, François. História do tempo presente e historiografia. Tempo e Argumento, revista do Programa de Pós-graduação em História, Florianópolis: UFSC, v.4, n.1, p.5-22, jan./jun. 2012.

DURKHEIM, Émile. Educação e sociologia. Trad. Stephania Matousek. Petrópolis: Vozes, 2013.

FICO, Carlos. História do Tempo Presente, eventos traumáticos e documentos sensíveis - o caso brasileiro. Varia Historia, Belo Horizonte: UFMG, v.28, n.47, p.43-59, jan./jun. 2012. Disponível em: http://www.scielo.br/pdf/vh/v28n47/03.pdf; Acesso em: 7 jul. 2017.

GABRIEL, Carmen Teresa. "Exercícios com documentos" nos livros didáticos de história: negociando sentidos da história ensinada na educação básica. In: ROCHA, Helenice A. B.; RESNIK, Luís; MAGALHÃES, Marcelo de S. A História na escola: autores, livros e leituras. Rio de Janeiro: Ed. FGV, 2009. p.243-253.

. Jogos do tempo e processos de identificação hegemonizados nos textos curriculares de História. Revista História Hoje, v.4, n.8, p.32-56, 2015. Disponível em: https://rhhj.anpuh.org/RHHJ/article/view/193; Acesso em: 2 jul. 2017.

LAMARÃO, Luisa Quarti. A crista é a parte mais superficial da onda: mediações culturais na MPB (1968-1982). Curitiba: Prismas, 2017. 
LIBÂNEO, José Carlos. O campo teórico e profissional da Didática hoje: entre Ítaca e o canto das sereias. In: ENCONTRO NACIONAL DE PRÁTICA DE ENSINO. ENDIPE, 15. Trajetórias e processos de ensinar e aprender. Didática e formação de professores. Anais... Rio Grande do Sul: Ed. PUCRS, 2008. p.234-251. Disponível em: http://www.scielo.br/scielo.php?script=sci_nlinks\&ref=000145\&pid=S010246 98201400040000900010\&lng=pt; Acesso em: 2 jul. 2017.

LOPES, Alice Ribeiro C. Conhecimento escolar: ciência e cotidiano. Rio de Janeiro: Ed. Uerj, 1999.

MAHEU, Cristina Maria D'Ávila T. Decifra-me ou te devoro: o que pode o professor frente ao manual escolar. Tese (Doutorado) - Universidade Federal da Bahia (UFBA). Salvador, 2001. Disponível em: http://www.anped.org.br/biblioteca/item/ decifra-me-ou-te-devoro-o-que-pode-o-professor-frente-ao-manual-escolar-0; Acesso em: 2 jul. 2017.

MARTINS, Franklin. Quem foi que inventou o Brasil? A música popular conta a história da república. (v.2, de 1964 a 1985). Rio de Janeiro: Nova Fronteira, 2015.

MATTOS, Ilmar Rohloff. “Mas não somente assim!” Leitores, autores, aulas como texto e o ensino-aprendizagem de História. Tempo. Dossiê Ensino de História, Rio de Janeiro: UFF - Departamento de História, v.11, n.21, p.5-16, jul./dez. 2006. Disponível em: http://www.scielo.br/pdf/tem/v11n21/v11n21a02.pdf; Acesso em: 5 jul. 2017.

MONTEIRO, Ana Maria F. da C. Aulas de História: questões do/no tempo presente. Educar em revista, Curitiba, n.58, p.165-182, out./dez. 2015. Disponível em: http:// www.scielo.br/scielo.php?script=sci_abstract\&pid=S010440602015000400165\&ln $\mathrm{g}=\mathrm{pt \& nrm}=$ iso; Acesso em: 2 jul. 2017.

.; PENNA, Fernando. Ensino de História: saberes em lugar de fronteira. Educação \& Realidade, Porto Alegre: FE/UFRGS, v.36, n.1, p.191-211, jan./abr. 2011. Disponível em: http://www.ufrgs.br/edu_realidade; Acesso em: 5 jul. 2017.

NAPOLITANO, Marcos. A história depois do papel. In: PINSKY, Carla Bassanezi (Org.) Fontes históricas. São Paulo: Contexto, 2005.

A MPB sob suspeita: a censura musical vista pela ótica dos serviços de vigilância política (1968-1981). Revista Brasileira de História, São Paulo, v.24, n.47, p.103-126, 2004.

ROCHA, Helenice. A aula como texto: historiografia e ensino de história. In: et al. A escrita da história escolar: memória e historiografia. Rio de Janeiro: Ed. FGV, 2009. p.13-31.

ROCHEDO, Aline do Carmo. Música e juventude: o rock nacional nos anos 1980. In: QUADRAT, Samantha (Org.) Não foi tempo perdido: os anos $80 \mathrm{em}$ debate. Rio de Janeiro: 7Letras, 2014. p.142-164. 
SARLO, Beatriz. Cenas da vida pós-moderna: intelectuais, arte, videocultura na Argentina. Trad. Sérgio Alcides. 5.ed. Rio de Janeiro: Ed. UFRJ, 2013.

SAVIANI, Dermeval. O legado educacional do regime militar. Cadernos Cedes, Campinas, v.78, n.76, p.291-312, set./dez. 2008. Disponível em: http://www.scielo. br/pdf/ccedes/v28n76/a02v2876.pdf; Acesso em: 2 jul. 2017.

SILVA, Daniel Pinha. O lugar do tempo presente na aula de história: limites e possibilidades. Revista Tempo e Argumento, Florianópolis, v.9, n.20, p.99-129, jan./abr. 2017. Disponível em: http://revistas.udesc.br/index.php/tempo/article/download/2175180309202017099/674; Acesso em: 5 jul. 2017.

SOARES, Olavo Pereira. A música nas aulas de história: o debate teórico sobre as metodologias de ensino. Revista História Hoje, v.6, n.11, p.78-99, 2017. Disponível em: https://rhhj.anpuh.org/RHHJ/article/view/325; Acesso em: 7 jul. 2017.

VILLAÇA, Mariana. Propostas metodológicas para a abordagem da canção popular como documento histórico. In: SIMPÓSIO LATINO-AMERICANO DE MUSICOLOGIA (SLAM), 2., 1999, Curitiba. Anais... Curitiba: Fundação Cultural, 1999.

NOTA

${ }^{1}$ Sobre a chamada MPB, os festivais da canção e a ação repressiva do regime ditatorial, ver NAPOLITANO (2004); LAMARÃO (2017); MARTINS (2015). Sobre o rock brasileiro na década de 1980, ver ROCHEDO (2014) e ALEXANDRE (2013).

Artigo recebido em 10 de julho de 2017. Aprovado em 16 de agosto de 2017. 